ORIGINAL ARTICLE

\title{
Effect on the process of care of an active strategy to implement clinical guidelines on physiotherapy for low back pain: a cluster randomised controlled trial
}

\author{
G E Bekkering, H J M Hendriks, M W van Tulder, D L Knol, M Hoeijenbos, R A B Oostendorp, \\ L M Bouter
}

Qual Saf Health Care 2005;14:107-112. doi: 10.1136/qshc.2003.009357

See end of article for authors' affiliations

Correspondence to:

Correspondence to:
Dr E Hendriks, Dutch Institute of Allied Health

Care, Research and

Development, P O Box

$1161,3800 \mathrm{BD}$

Amersfoort, The

Netherlands; Hendriks@

paramedisch.org or

erik.hendriks@

epid.unimaas.nl

Accepted for publication 23 July 2004
Objectives: To evaluate the effect on the process of care of an active strategy to implement clinical guidelines on physiotherapy for low back pain.

Design: A cluster randomised controlled trial comparing an active strategy with standard dissemination. Setting: Primary care physiotherapy practices.

Participants: 113 physiotherapists were randomly allocated to receive the guidelines by mail (control group) or to receive an additional active strategy (intervention group) which consisted of a multifaceted programme including education, discussion, role playing, feedback, and reminders.

Main outcome measures: Adherence to the guidelines was measured by means of individual patients' forms recording the treatment completed by the physiotherapist. The forms were assessed using an algorithm based on the number of treatment sessions, treatment goals, interventions, and patient education.

Results: Physiotherapists in the intervention group more often correctly limited the number of treatment sessions for patients with a normal course of back pain (OR 2.39; $95 \% \mathrm{Cl} 1.12$ to 5.12 ), more often set functional treatment goals (OR $1.99 ; 95 \% \mathrm{Cl} 1.06$ to 3.72 ), more often used mainly active interventions (OR 2.79; $95 \% \mathrm{Cl} 1.19$ to 6.55 ), and more often gave adequate patient education (OR $3.59 ; 95 \% \mathrm{Cl} 1.35$ to 9.55 ). They also adhered more to all four criteria (OR 2.05; $95 \% \mathrm{Cl} 1.15$ to 3.65 ).

Conclusions: The active strategy moderately improved adherence to the guidelines. Active strategies are recommended to implement the clinical guidelines on physiotherapy for low back pain.
$\mathrm{T}$ he increasing number of clinical guidelines may be attributed to the growing importance of evidence based medicine for all health professions including physiotherapy. Clinical guidelines can support physiotherapists in putting evidence based medicine into daily practice because they give an overview of the available evidence for physiotherapeutic diagnostic and therapeutic decisions. To assist physiotherapists in making evidence based decisions in practice with respect to low back pain, clinical guidelines on physiotherapy have been developed in the Netherlands ${ }^{1}$ with standard dissemination by mail.

The concept of low back pain in these guidelines refers to non-specific low back pain, defined as low back pain without a specified physical cause-for example, nerve root compression, trauma, infection, or tumour. ${ }^{2}$ The guidelines recommend an active treatment approach in which the physiotherapist gives information so the patient learns to take control over his/her back pain. For patients with a normal course, adequate information and the advice to stay active are the most important recommendations. For patients with an abnormal course, exercise therapy should be provided in addition with a behavioural approach if necessary $^{1}$ (normal and abnormal course are defined in legend to fig 1).

The publication and dissemination of guidelines does not automatically result in their use in practice ${ }^{3}$ and changing practice. Some form of implementation therefore has to take place. It is not clear what is the most effective strategy for the implementation of clinical guidelines in the field of physiotherapy. ${ }^{3}$ However, it is obvious that a passive intervention such as postal dissemination is unlikely to change practice. ${ }^{45}$
A survey, which was part of the development process of these guidelines, showed that there were several important barriers for their implementation. ${ }^{6}$ An active multifaceted strategy has therefore been developed to help physiotherapists to implement the clinical guidelines for low back pain. This paper describes a randomised controlled trial that was carried out to evaluate the effects of this strategy on the process of care and the adherence of physiotherapists to the main recommendations contained in the guidelines.

\section{METHODS}

From May 2001 to December 2002 a randomised controlled trial was performed among physiotherapists in the Netherlands. The study was approved by the medical ethics committee of the VU University Medical Center in Amsterdam.

\section{Sample size calculation}

The calculation of sample size was based on the ability to detect a difference of $20 \%$ in adherence between the two groups, which was considered to be an important difference. It was adjusted for the effect of clustering using an intraclass correlation of $0.05^{7}$ and an estimated cluster size of five patients per practice. In total, a sample of 284 patients and/or 48 practices were needed (two sided $\alpha=0.05, \beta=0.20$ ).

\section{Recruitment of physiotherapists}

The Royal Dutch Society for Physiotherapy randomly selected, from all their members with private practices $(n=6261), 325$ practices located in the centre of the Netherlands. These practices received a letter and, if 
necessary, a follow up telephone call, explaining the purpose and methods of the study and inviting them to participate. Physiotherapists were eligible for participation if they worked in a private practice in primary care and if they expected to treat at least five patients with low back pain during the enrolment period.

\section{Randomisation}

Participating practices were randomly allocated to one of the two groups. Block randomisation (blocks of four practices) was carried out after pre-stratification for the work setting (solo/duo practices versus group practices). A statistician, who was not involved in this trial, drew up an allocation schedule using a computerised random number generator. The primary investigator (GEB), without any knowledge of the practices, listed them alphabetically according to the name of their street address, and subsequently assigned them to the intervention or control group using the allocation schedule.

\section{Recruitment of patients}

All participating physiotherapists were asked to include a maximum of 10 consecutive patients who were (for the first time or again) referred for physiotherapy for a new episode of non-specific low back pain. Patients with incident or recurrent low back pain could therefore participate. Patients were eligible for inclusion if the physiotherapist confirmed that the diagnosis was non-specific low back pain and if the patient was able to complete questionnaires in the Dutch language. Patients who were pregnant were excluded, as were those considered by the physiotherapist to be at high risk for dropping out of the study due to psychological problems. All patients gave written informed consent.

\section{Standard dissemination}

All physiotherapists received the clinical guidelines via the standard method of dissemination used by the Royal Dutch Society for Physiotherapy. This implies that they received the guidelines by mail together with four forms: a self-evaluation form to assess whether their current management was consistent with the recommendations contained in the clinical guidelines, two forms facilitating discussion with other physiotherapists and general practitioners respectively, and a copy of the Quebec Back Pain Disability Scale. ${ }^{89}$ A summary of the clinical guidelines was also provided. At the same time an article about the development of the guidelines was published in a Dutch professional journal for physiotherapists. ${ }^{10}$

\section{Active strategy}

The physiotherapists in the intervention group additionally participated in an active strategy to implement the clinical guidelines which consisted of two training sessions, each lasting 2.5 hours, for groups of 8-12 physiotherapists. For each session a preparation time of 2 hours was recommended. The sessions were based on interventions that have all been shown to be effective, such as interactive education and discussion, feedback, and reminders. ${ }^{5}{ }^{11-14}$ The content of the strategy was determined on the basis of information about the expected barriers for implementation gathered during the development of the clinical guidelines. ${ }^{6}$ Two experts gave advice on the content of the strategy. The goals and content of the strategy are shown in box 1 .

The primary investigator and one of two additional trainers with adequate clinical experience in the management of low back pain supervised the training sessions.
Box 1 Active strategy to implement clinical guidelines on physiotherapy for low back pain

Goal

To improve the knowledge, skills and attitude of physiotherapists towards evidence based physiotherapy for low back pain

Content

Session 1:

- a didactic overview of the diagnostic and treatment processes: overview of the evidence and consequences of the evidence for diagnostic and therapeutic management compared with their own current management;

- questions and discussion (interactive);

- two examples of role playing with an actor-one on the diagnostic process and one on the treatment process.

A 4 week interval in which the physiotherapists were expected to implement the guidelines in practice. They were also asked to complete a registration form about their current management of patients with low back pain.

Session 2:

- discussion of experiences with implementing the guidelines in practice;

- feedback on current management;

- two reminders with respect to evidence based patient education.

\section{Evaluation instruments and procedures}

All physiotherapists were asked to complete a registration form for each patient containing questions on the following items:

- history taking and physical examination;

- treatment goals;

- content of the treatment (which interventions were given, frequency and proportion of the intervention in relation to the total treatment, which information/education was given); and

- total number of sessions of the treatment episode.

The algorithm developed to assess the process of care consisted of the four criteria on the main recommendations contained in the clinical guidelines (fig 1).

\section{Blinding}

Two reviewers independently assessed the registration form using the algorithm without being aware of the group allocation. In total, four reviewers assessed the forms (GEB, HJMH, RABO, MWT). Before the final scoring five cases were used for a pilot assessment and these were blinded again afterwards. In case of disagreement between the two reviewers, a method was used to discuss and resolve the disagreement by consensus. If the disagreement persisted, a third reviewer made the final decision.

\section{Analysis of data}

The baseline characteristics of the physiotherapists and patients in the two groups were compared using $\chi^{2}$, unpaired Student's $t$ tests, or Mann-Whitney U tests. The proportion of patients for whom each and all four criteria were fulfilled was 


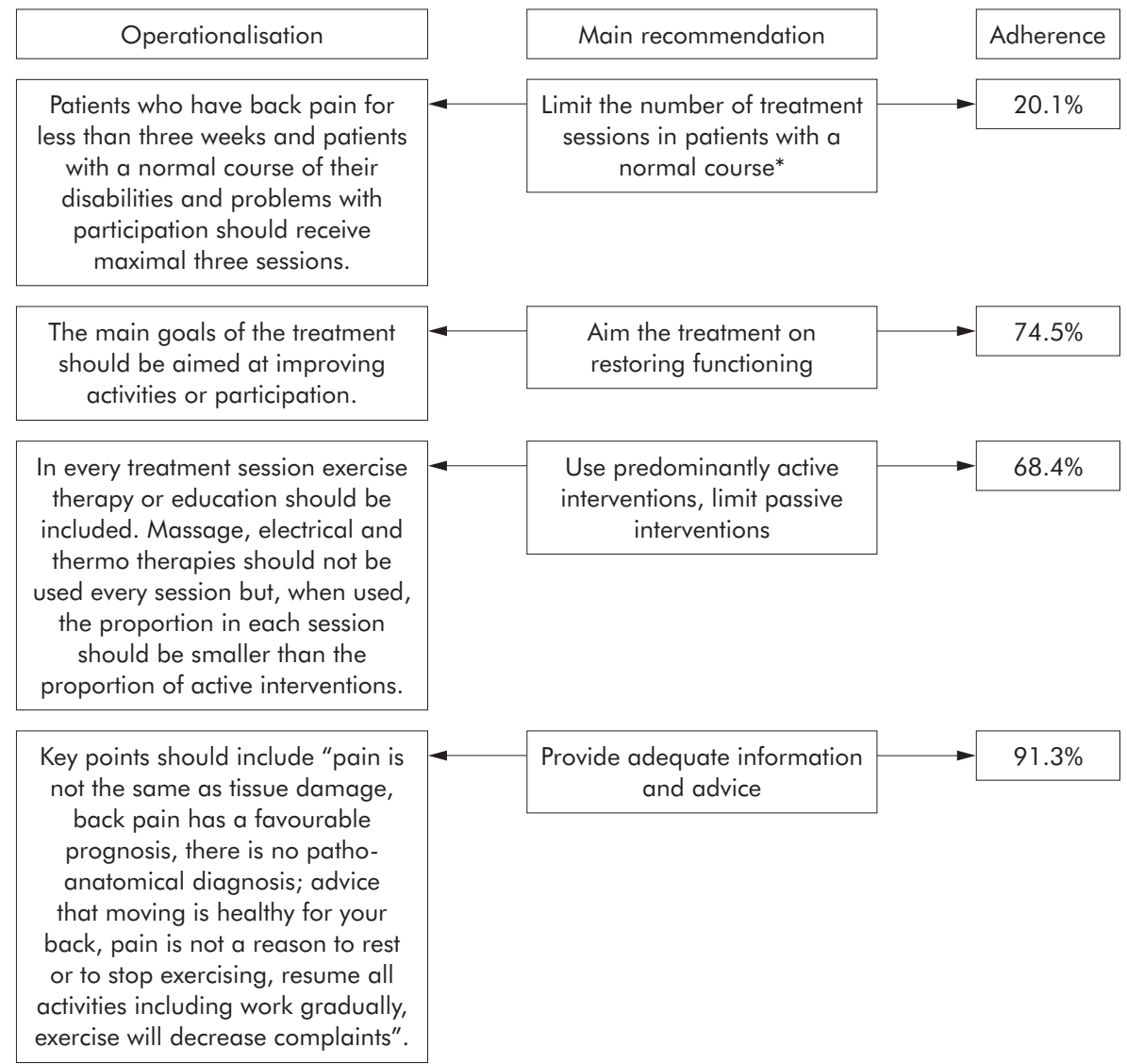

Figure 1 Main recommendations in the guidelines, operationalisation, and overall proportion of adherence. *Only calculated for patients with a normal course $(n=229)$. Patients with a normal course of low back pain have low back pain with a maximum duration of 3 weeks or show improvement in their physical functioning over the previous 3 weeks. Patients with an abnormal course of low back pain have low back pain for more than 3 weeks with no signs of improvement in the level of physical functioning.'

calculated. Cohen's kappa was used to calculate agreement between the pairs of reviewers of the registration forms.

To determine the effectiveness of the active strategy, logistic multilevel analysis was performed to adjust for clustering of data. ${ }^{15}$ Three levels were defined in the multilevel analysis: (1) patient, (2) physiotherapist, (3) practice. The regression coefficients were transformed to odds ratios using $\mathrm{e}^{\mathrm{B}}$, indicating the effect of the intervention. The analyses were adjusted for a potentially strong confounder-namely, postgraduate education on low back pain. All multilevel analyses were performed with MLwiN Version $1.10 .^{16}$

The analysis was performed on the "intention to treat" principle. Thus, all patients who were treated by physiotherapists in the intervention group were included in the analysis regardless of whether or not their physiotherapist had attended both training sessions.

\section{RESULTS}

\section{Characteristics of physiotherapists and patients}

A total of 113 physiotherapists from 68 practices agreed to participate. Figure 2 shows the flow of participants during the study. Six physiotherapists dropped out immediately after randomisation; these were more often working in a solo/duo practice $(\mathrm{p}=0.038$, table 1$)$. Physiotherapists in the intervention group were slightly older $(p=0.011)$, but there were no other differences between the two groups. A total of 500 patients were included. There were no differences in patient characteristics between the two groups (table 2).

\section{Effect of the intervention}

The physiotherapists in the intervention group more often correctly limited the number of treatment sessions for patients with a normal course of back pain (OR 2.39; 95\% CI 1.12 to 5.12), more often set functional treatment goals (OR $1.99 ; 95 \%$ CI 1.06 to 3.72 ), more often used mainly active interventions (OR 2.79; 95\% CI 1.19 to 6.55 ), and more often gave adequate patient education (OR 3.59; 95\% CI 1.35 to 9.55) Physiotherapists in the intervention group also adhered more to all four recommendations of the guidelines (OR 2.05; 95\% CI 1.15 to 3.65 ; table 3 ).

The adherence to all criteria was $42 \%$ in the intervention group and $30 \%$ in the control group. Overall, $63 \%$ of the variance was at patient level, $27 \%$ at physiotherapist level, and $9 \%$ at practice level. The recommendation to limit the number of sessions for patients with a normal course of low back pain had the lowest adherence (13-27\%) and the recommendation to give adequate information had the highest (87-96\%).

Cohen's kappa for agreement of the separate criteria between all pairs of reviewers varied between 0.85 (95\% CI 0.80 to 0.90 ) and 0.38 (95\% CI 0.25 to 0.50 ) (table 3). For approximately $9 \%$ of the forms a third reviewer was consulted to make a final decision.

\section{DISCUSSION}

This study shows that an active strategy is an important element in the implementation of clinical guidelines on low back pain. The active strategy resulted in a moderate 


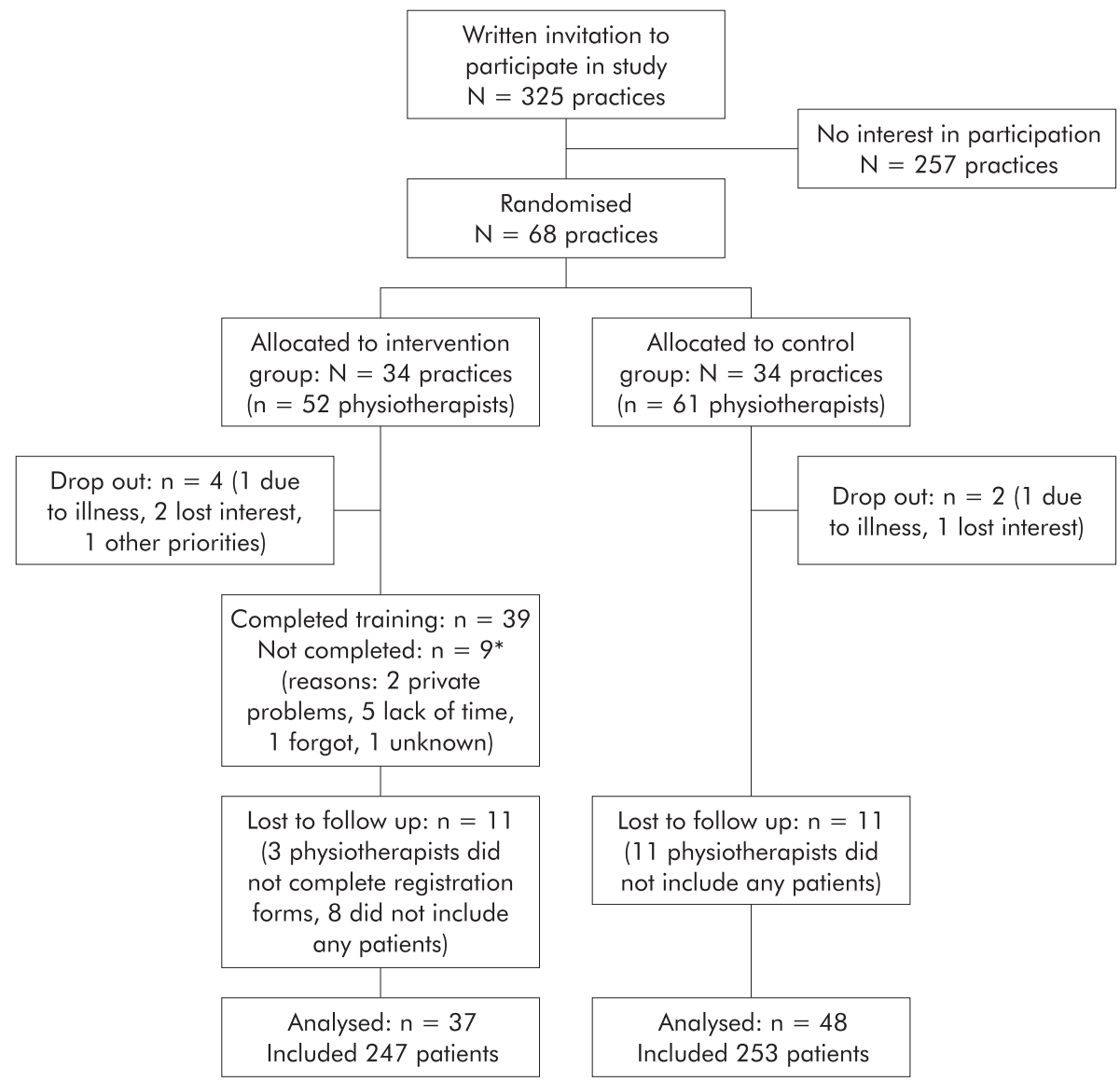

Figure 2 Diagram showing the flow of practices $(N)$ and physiotherapists $(n)$ through the trial.

improvement in overall adherence, but there is still room for further improvement. The finding that adherence to separate criteria was much higher shows that, in practice, some aspects of evidence based care are already being applied.

The main strength of this study is the cluster randomised and controlled design which strengthens the conclusions. Blind assessment was also made of the outcome "adherence to the guidelines" because self-reports on adherence to clinical guidelines are reported to be subject to bias. ${ }^{17}$

One limitation of this study is that the physiotherapists were self-selected so those who agreed to participate may have been more motivated or may have had a more positive attitude towards clinical guidelines. These characteristics may imply a readiness to change which is considered as the first step in the process of changing professional behaviour. ${ }^{18}$ This self-selection may result in less room for improvement, but also in an increased effect of the intervention. The gap between evidence based practice and current practice in the treatment of low back pain might be larger in a random group of physiotherapists.

This is the first study to report the effects of an active strategy to implement clinical guidelines on physiotherapy. The results of studies from other disciplines frequently show positive effects of multifaceted implementation interventions on adherence to the recommendations of guidelines. ${ }^{19}$ Evidence from other disciplines supports the recommendation for an evidence based implementation of guidelines in the physiotherapy profession. ${ }^{20}$

Table 1 Characteristics of physiotherapists in the intervention and control groups and of those who dropped out before enrolling patients

\begin{tabular}{|c|c|c|c|c|}
\hline & $\begin{array}{l}\text { Intervention } \\
\text { group } \\
(\mathrm{n}=48 \text { ) }\end{array}$ & $\begin{array}{l}\text { Control group } \\
(n=59)\end{array}$ & $\begin{array}{l}\text { Total } \\
(n=107)\end{array}$ & $\begin{array}{l}\text { Drop out } \\
(n=6)\end{array}$ \\
\hline Mean (SD) age (years) & $43.1(8.6)^{*}$ & $38.7(8.8)$ & $40.7(8.9)$ & $41.0(6.6)$ \\
\hline Sex: no (\%) female & $22(45.8 \%)$ & $24(40.7 \%)$ & $46(43.0 \%)$ & $3(50.0 \%)$ \\
\hline Practice: no (\%) solo/duo & $14(29.2 \%)$ & $15(25.4 \%)$ & $29(27.0 \%)$ & $4(66.7 \%) \dagger$ \\
\hline Mean (SD) experience (years) & $15.7(8.8)$ & $14.1(8.3)$ & $14.8(8.5)$ & $14.2(6.9)$ \\
\hline $\begin{array}{l}\text { No (\%) postgraduate education } \\
\text { on low back pain }\end{array}$ & $36(75.0 \%)$ & $41(69.5 \%)$ & $77(74.0 \%)$ & $3(50.0 \%)$ \\
\hline $\begin{array}{l}\text { No }(\%) \text { postgraduate education } \\
\text { on chronic pain }\end{array}$ & $0(0 \%)$ & $4(6.8 \%)$ & $4(5.2 \%)$ & $0(0 \%)$ \\
\hline
\end{tabular}


Table 2 Characteristics of study patients

\begin{tabular}{lll}
\hline & $\begin{array}{l}\text { Intervention group } \\
(\mathbf{n}=\mathbf{2 4 7 )}\end{array}$ & $\begin{array}{l}\text { Control group } \\
(\mathbf{n}=\mathbf{2 5 3})\end{array}$ \\
\hline Mean (SD) age (years) & $46.2(14.8)$ & $44.4(13.3)$ \\
Sex: no (\%) female & $132(53.4 \%)$ & $127(50.2 \%)$ \\
No (\%) with paid job & $171(69.1 \%)$ & $193(77.0 \%)$ \\
Duration of current episode*: no (\%) & $85(35.6 \%)$ & $74(29.2 \%)$ \\
$\quad 3$ weeks & $76(31.8 \%)$ & $93(39.1 \%)$ \\
$4-12$ weeks & $78(32.6 \%)$ & $71(29.8 \%)$ \\
$\begin{array}{l}\text { P12 weeks } \\
\text { Mean (SD) baseline functioning }\end{array}$ & $39.3(17.9)$ & $41.0(18.6)$ \\
(QBPDS) score & $6.3(2.1)$ & $6.4(2.1)$ \\
Mean (SD) baseline pain intensity & 46.6 & 43.2 \\
(NRS) score & & \\
Baseline sick leave due to & & \\
back pain (\% yes) & & \\
\hline QBPDS, Quebec Back Pain Disability Scale (0-100: higher score means more disabilities); NRS, Numerical Rating \\
Scale (0-10: higher score means more pain). \\
*Missing values (8 and 15, respectively).
\end{tabular}

We defined an important difference in guideline adherence as $20 \%$. This estimation was based on the results of our survey $^{6}$ and on reviews showing improvements in the process of care ranging from $0 \%$ to over $39 \%{ }^{12}$ It is not clear what percentage is adequate to define an important difference in guideline adherence. This will depend, for example, on the baseline guideline adherence, the way adherence is measured, and the effects of an improvement in adherence on patient outcome. However, our expectation of $20 \%$ improvement may be too optimistic. This is supported by our findings that adherence to the guidelines in the control group was higher than expected. A more recent review considers that improvements in the process of care following guideline implementation are usually $5-10 \% .^{21}$ The issue of a clinically relevant improvement in implementation trials needs further consideration.

Although it is also not entirely clear when adherence to guidelines is good or inadequate, the adherence to these guidelines seems fair to good for three of the four recommendations. For most patients functional goals are set, predominantly active interventions are applied, and adequate information is provided. This is in contrast to the results of our survey, even more as it has been shown that Dutch physiotherapists have already changed their management of low back pain from mainly passive interventions in $1990^{22}$ to predominantly active interventions in the year $2000 .^{23}$ This probably results from self-selection of the physiotherapists.

The main problem in adherence with these clinical guidelines is related to the limitation of treatment sessions for patients with a normal course of low back pain. This is recommended because there is evidence that providing no treatment in the acute phase can have a positive influence on the natural course, and that early treatment is of no benefit. ${ }^{24}$ There has been much debate on the effectiveness of spinal manipulation as early treatment, as shown by inconsistent recommendations in guidelines worldwide. ${ }^{25}$ Recent reviews concluded that, although manipulation reduces pain compared with sham treatments, it is not superior to other treatments for patients with back pain. ${ }^{26} 27$

Although a $100 \%$ adherence rate is not expected in health care due to individual characteristics of patients, this study shows that physiotherapists must learn to be more reserved in patients with a normal course. Putting more emphasis on self-management may help to prevent unnecessary costs and somatisation (the expression of psychological problems as physical symptoms) of patients. However, because this implies a major shift in the management policies of physiotherapists (who are trained to treat patients), it may

\section{Key messages}

- The physiotherapy profession has become aligned with the principles of evidence based medicine using guideline development and implementation.

- A cluster randomised controlled trial showed better adherence to guidelines by physiotherapists who had received an active implementation strategy.

- Active multifaceted implementation strategies are valuable, but the effects are modest.

- Assessment of reasons for non-adherence to guidelines should be used to further improve implementation.

Table 3 Effect of the strategy, percentage of patients for whom each and all recommendations of the guidelines were fulfilled, and agreement of the reviewers in assessing the registration forms

\begin{tabular}{|c|c|c|c|c|}
\hline $\begin{array}{l}\text { Recommendation } \\
\text { (no (\%) fulfilled) }\end{array}$ & $\begin{array}{l}\text { Effect of strategy } \\
\text { OR }(95 \% \mathrm{CI})^{*}\end{array}$ & $\begin{array}{l}\text { Intervention group } \\
(\mathrm{n}=247)\end{array}$ & $\begin{array}{l}\text { Control group } \\
(n=253)\end{array}$ & $\begin{array}{l}\text { Agreement } \\
\text { kappa }(95 \% \mathrm{Cl})\end{array}$ \\
\hline $\begin{array}{l}\text { Limit number of sessions in } \\
\text { normal courset }\end{array}$ & $2.39(1.12$ to 5.12$)$ & $32(27 \%)$ & $14(13 \%)$ & $0.85(0.80$ to 0.90$)$ \\
\hline Set functional treatment goals & 1.99 (1.06 to 3.72$)$ & $188(79 \%)$ & $180(71 \%)$ & $0.60(0.52$ to 0.67$)$ \\
\hline Use manly active interventions & $2.79(1.19$ to 6.55$)$ & $183(77 \%)$ & $154(60 \%)$ & $0.59(0.51$ to 0.67$)$ \\
\hline Give adequate information & 3.59 (1.35 to 9.55$)$ & $229(96 \%)$ & $221(87 \%)$ & $0.38(0.25$ to 0.50$)$ \\
\hline All four recommendations $\ddagger$ & 2.05 (1.15 to 3.65$)$ & $96(42 \%)$ & $75(30 \%)$ & \\
\hline
\end{tabular}

OR, odds ratio; $\mathrm{Cl}$, confidence interval.

${ }^{*}$ Adjusted for postgraduate education.

†Calculated for patients with normal course only (intervention group: $n=122$; control group: $n=107$ ).

$\ddagger$ For patients with an abnormal course these percentages represent adherence to all three recommendations. 
take more time and effort to achieve. To improve implementation, reasons for non-adherence should be further investigated.

Measuring the process of care or guideline adherence is challenging. Our study showed that judging whether physiotherapists give adequate information and advice was the subject of much discussion which is reflected by the low kappa value between assessors. We found that there are several ways to judge the information given-for example, a global judgement as to whether the information is mostly adequate or a judgement that it is only adequate if certain information topics have been discussed. These criteria need further standardisation.

Future research will need to obtain more detailed information about the effectiveness of strategies to implement clinical guidelines-for example, which strategies can be omitted from multifaceted interventions to make them more successful in improving adherence and which specific strategies should be selected for physiotherapists. It may also need to focus on ways of improving the attitudes of physiotherapists towards clinical guidelines and the skills needed to make them aware of the principles of evidence based practice, which are alternatives for the translation of evidence into clinical practice.

\section{ACKNOWLEDGEMENTS}

The authors gratefully acknowledge the contribution made by Arno J Engers to the design of the active strategy and in supervising the training sessions. They are also grateful to Michel Wensing for his helpful comments on the active strategy.

\section{Authors' affiliations \\ G E Bekkering, Dutch Institute of Allied Health Care, Amersfoort and Institute for Research in Extramural Medicine, VU University Medical} Center, Amsterdam, The Netherlands

H J M Hendriks, Dutch Institute of Allied Health Care, Amersfoort and Department of Epidemiology, Maastricht University, The Netherlands M W van Tulder, Institute for Research in Extramural Medicine, VU University Medical Center, Amsterdam and Department of Clinical Epidemiology and Biostatistics, VU University Medical Center, Amsterdam, The Netherlands

D L Knol, Institute for Research in Extramural Medicine, VU University Medical Center, Amsterdam, The Netherlands

M Hoeijenbos, Institute for Medical Technology Assessment, Erasmus University, Rotterdam, The Netherlands

R A B Oostendorp, University Medical Center, Centre of Quality of Care Research, Nijmegen; Dutch Institute of Allied Health Care, Amersfoort, The Netherlands and Free University of Brussels, Faculty of Medicine and Pharmacology, Postgraduate Education Manual Therapy, Brussels, Belgium

L M Bouter, Institute for Research in Extramural Medicine, VU University Medical Center, Amsterdam, The Netherlands

This study was supported by a grant from the Ministry of Health, Welfare and Sports.

GEB, HJMH, MWvanT, DLK, MH, RABO, LMB conceived and designed the study and critically revised the manuscript; GEB collected and assembled the data; GEB, HJMH, MWvanT and DLK analysed and interpreted the data; HJMH, MWvanT, MH, RABO, LBM obtained funding. All authors will act as guarantor for this paper.

\section{REFERENCES}

1 Bekkering GE, Hendriks HJM, Koes BW, et al. Dutch physiotherapy guidelines for low back pain. Physiotherapy 2003;89:82-96.

2 Waddell G. The back pain revolution. Philadelphia: Churchill Livingstone 1998.

3 Gross PA, Greenfield S, Cretin S, et al. Optimal methods for guideline implementation: conclusions from Leeds Castle meeting. Med Care 2001;39:II85-92.

4 Woolf SH, Grol R, Hutchinson A, et al. Clinical guidelines: potential benefits, limitations, and harms of clinical guidelines. BMJ 1999;318:527-30.

5 Wensing M, Van der Weijden T, Grol R. Implementing guidelines and innovations in general practice: which interventions are effective? $\mathrm{Br} J \mathrm{Gen}$ Pract 1998;48:991-7.

6 Bekkering GE, Engers AJ, Wensing $M$, et al. Development of an implementation strategy for the physiotherapy guideline on low back pain. Aust J Physiother 2003;49:208-14.

7 DSI. Changing professional practice. Theory and practice of clinical guidelines implementation. Copenhagen: Danish Institute for Health Services Research and Development, 1999

8 Kopec JA, Esdaile JM, Abrahamowicz M, et al. The Quebec Back Pain Disability Scale. Measurement properties. Spine 1995;20:341-52.

9 Schoppink LE, Van Tulder MW, Koes BW, et al. Reliability and validity of the Dutch adaptation of the Quebec Back Pain Disability Scale. Phys Ther 1996;76:268-75

10 Bekkering GE, Hendriks HJM, Oostendorp RAB. Clinical guidelines on physiotherapy for low back pain have been published. [In Dutch: Richtlijn Lage-rugpiin gepubliceerd]. FysioPraxis 2001;4:28-31.

11 Davis DA, Thomson MA, Oxman AD, et al. Changing physician performance. A systematic review of the effect of continuing medical education strategies. JAMA 1995;274:700-5.

12 Grimshaw J, Freemantle N, Wallace S, et al. Developing and implementing clinical practice guidelines. Qual Health Care 1995;4:55-64.

13 Bero LA, Grilli R, Grimshaw JM, et al. Closing the gap between research and practice: an overview of systematic reviews of interventions to promote the implementation of research findings. The Cochrane Effective Practice and Organization of Care Review Group. BMJ 1998;317:465-8.

14 Davis DA, Taylor-Vaisey A. Translating guidelines into practice. A systematic review of theoretic concepts, practical experience and research evidence in the adoption of clinical practice guidelines. Can Med Assoc J 1997; 157:408-16.

15 Snijders TAB, Bosker RJ. Multilevel analysis: an introduction to basic and advanced multilevel modeling. London: Sage, 1999.

16 Rasbash J, Browne W, Goldstein H, et al. A user's guide to MLwiN. version 2.1d for use with MLwiN 1.10. London: Centre for Multilevel Modeling Institute of Education, University of London, 2000.

17 Adams AS, Soumerai SB, Lomas J, et al. Evidence of self-report bias in assessing adherence to guidelines. Int J Qual Health Care 1999;11:187-92.

18 Moulding NT, Silagy CA, Weller DP. A framework for effective management of change in clinical practice: dissemination and implementation of clinical practice guidelines. Qual Health Care 1999;8:177-83.

19 Grimshaw JM, Shirran L, Thomas R, et al. Changing provider behavior: an overview of systematic reviews of interventions. Med Care 2001;39:112-45.

20 Grol R, Grimshaw J. Evidence-based implementation of evidence-based medicine. Jt Comm J Qual Improv 1999;25:503-13.

21 Grol R. Improving the quality of medical care. Building bridges among professional pride, payer profit, and patient satisfaction. JAMA 2001;286:2578-85.

22 Van der Valk RWA, Dekker J, Van Baar ME. Physical therapy for patients with back pain. Physiotherapy 1995;81:345-51

23 Engers AJ, Schers H, Oostendorp RAB, et al. Management of Dutch physiotherapists in patients with low back pain (in Dutch). Ned Tijdschr Fysiother 2001;111:142-51.

24 Van Tulder MW, Malmivaara A, Esmail R, et al. Exercise therapy for low back pain. Cochrane Database Syst Rev 2000;CD000335.

25 Koes BW, Van Tulder MW, Ostelo R, et al. Clinical guidelines for the management of low back pain in primary care: an international comparison. Spine $2001 ; 26: 2504-13$.

26 Assendelft WJJ, Morton SC, Yu El, et al. Spinal manipulative therapy for low back pain. A meta-analysis of effectiveness relative to other therapies. Ann Intern Med 2003;138:871-81.

27 Cherkin DC, Sherman KJ, Deyo RA, et al. A review of the evidence for the effectiveness, safety, and cost of acupuncture, massage therapy, and spinal manipulation for back pain. Ann Intern Med 2003;138:906. 